\title{
An Inhibitory Septum to Lateral Hypothalamus Circuit That Suppresses Feeding
}

\author{
Patrick Sweeney and $\odot$ Yunlei Yang \\ Department of Neuroscience and Physiology, State University of New York Upstate Medical University, Syracuse, New York 13210
}

Feeding behavior is orchestrated by neural circuits primarily residing in the hypothalamus and hindbrain. However, the relative influence of cognitive and emotional brain circuits to the feeding circuitry in the hypothalamus and hindbrain remains unclear. Here, using the cell-type selectivity of genetic methods, circuit mapping, and behavior assays, we sought to decipher neural circuits emanating from the septal nucleus to the lateral hypothalamus (LH) that contribute to neural regulation of food intake in mice. We found that chemogenetic and optogenetic activation of septal vesicular GABA transporter (vGAT)-containing neurons or their projections in the LH reduced food intake in mice. Consistently, chemogenetic inhibition of septal vGAT neurons increased food intake. Furthermore, we investigated a previously unknown neural circuit originating from septal vGAT neurons to a subset of vGAT neurons in the LH, an area involved in homeostatic and hedonic control of energy states. Collectively, our data reveal an inhibitory septohypothalamic feeding circuit that might serve as a therapeutic target for the treatment of eating disorders such as anorexia nervosa.

Key words: chemogenetics; food intake; lateral hypothalamus; optogenetics; septum

\section{Significance Statement}

Our results demonstrate that top-down projections from the septum to the hypothalamus control food intake negatively. Given the known role for both of these brain regions in the control of feeding and emotion-related behaviors, these findings reveal previously unknown neural circuitry that is likely implicated in emotional aspects of food intake and provide new insights into the development of therapeutic targets for the treatment of eating disorders.

\section{Introduction}

Feeding behavior is an essential motivational process that is controlled in the CNS by highly redundant and overlapping neural circuits (Williams and Elmquist, 2012; Schwartz and Zeltser, 2013; Sternson et al., 2013; Sternson and Atasoy, 2014). In addition to classical hypothalamic brain regions associated with feeding, recent studies have indicated that septohippocampal brain regions, including ventral hippocampus (vHPC) and septum, are involved in the control of feeding (Scopinho et al., 2008; Davidson et al., 2009; Kanoski et al., 2013; Mitra et al., 2014; Parent et al., 2014; Hsu et al., 2015; Sweeney and Yang, 2015; Urstadt et al., 2015; Terrill et al., 2016). For example, our recent study demon-

\footnotetext{
Received June 27, 2016; revised Aug. 7, 2016; accepted Sept. 2, 2016.

Author contributions: P.S. and Y.Y. designed research; P.S. and Y.Y. performed research;P.S. and Y.Y. contributed unpublished reagents/analytic tools; P.S. and Y.Y. analyzed data; P.S. and Y.Y. wrote the paper.

This work was supported by the State University of New York and the National Institutes of Health (Grant R01 MH109441A to Y.Y.). We thank B. Knox, E. Solessio, F. Middleton, R. Matthews, and all the members of Yang laboratory for discussion and critical comments on this project; R. Quinn for mouse husbandry; and A. Matiukas for help with imaging.

The authors declare no competing financial interests.

Correspondence should be addressed to Yunlei Yang, Department of Neuroscience and Physiology, State University of New York Upstate Medical University, 505 Irving Avenue, Syracuse, NY 13210. E-mail:yangyun@upstate.edu. DOI:10.1523/JNEUROSCI.2042-16.2016

Copyright $\odot 2016$ the authors $\quad 0270-6474 / 16 / 3611185-11 \$ 15.00 / 0$
}

strated that the vHPC reduces appetite by sending glutamatergic neuronal projections to the septum (Sweeney and Yang, 2015) and infusions of glucagon-like-peptide 1 (GLP-1) reduce feeding (Terrill et al., 2016). In addition, the septum projects to critical feeding centers in the brain (Sheehan et al., 2004; Urstadt and Stanley, 2015) and is known to be involved in gastric emptying after meal consumption (Gong et al., 2013).

Although recent studies have suggested a role for the septum in the control of feeding, the involved neural circuits remain unknown. The septum projects to multiple hypothalamic brain regions involved in feeding (Sheehan et al., 2004; Urstadt and Stanley, 2015). Particularly dense septal projections are observed in the lateral hypothalamus (LH), a brain region classically considered to be involved in motivational aspects of feeding (Stuber and Wise, 2016). For example, both electrolytic and chemical lesions of LH reduce feeding (Anand et al., 1951; Grossman et al., 1978; Stricker et al., 1978; Grossman et al., 1982), whereas electrical stimulation of LH produces voracious feeding (Delgado et al., 1953). Extensive studies have demonstrated that LH modulates motivational aspects of feeding and reward via tight interactions with the mesolimbic dopamine system (Wise et al., 1978; Wise et al., 1981; Yeomans, 1982; Nieh et al., 2015; Barbano et al., 2016; Nieh et al., 2016). Interestingly, LH is also primed to inte- 
grate signal inputs related to homeostatic aspects of feeding behavior via connections within homeostatic feeding centers, including the arcuate nucleus and paraventricular nucleus of the hypothalamus (Betley et al., 2013; Wu et al., 2015). Given the well described role of LH in the control of feeding and other motivated behaviors and strong septal projections in the LH, we investigated whether and how septal inputs to $\mathrm{LH}$ regulate food intake. Because distinct neurons within LH have been shown to have opposing and specialized roles in the control of feeding (Brown et al., 2015; Stuber and Wise, 2016), we investigated the putative postsynaptic neuron targets in LH that mediate the septum's effects on feeding. It is well demonstrated that activation of GABAergic neurons in LH increases appetitive and consummatory behaviors (Jennings et al., 2015; Navarro et al., 2015; Nieh et al., 2015; Wu et al., 2015; Barbano et al., 2016; Nieh et al., 2016). Because GABAergic transmission in LH has been shown previously to reduce feeding (Kelly et al., 1979; O'Connor et al., 2015), we reasoned that GABAergic neurons in septum reduce feeding by inhibiting LH GABAergic neurons.

In this study, we sought to determine the role of a neurochemically distinct population of septal neurons that express the GABAergic neural marker vesicular GABA transporter (vGAT) in the regulation of food intake and to identify downstream targets within the LH that mediate these effects. We found that chemogenetic and optogenetic activation of vGAT-expressing neurons within the septum suppress food intake, whereas inhibition of these neurons increases feeding. Subsequent optogeneticassisted circuit mapping experiments revealed that septal vGAT neurons exert suppressive effects on feeding by projecting to $\mathrm{LH}$ and that a subset of septal vGAT neurons provide functional inhibitory connections to hyperphagia-inducing vGAT neurons in LH. Collectively, our results demonstrate a previously unknown circuit for "top-down" septohypothalamic suppression of appetite, providing new and important insights into neural control of feeding behavior.

\section{Materials and Methods Protocol}

All experiments were performed in agreement with the guidelines described by the National Institutes of Health's Guide for the Care and Use of Laboratory Animals and were approved by the Institutional Animal Care and Use Committee at State University of New York Upstate Medical University.

\section{Mice}

Adult male and female C57BL/6J and vGAT-Cre mice (5-8 weeks old) were used for all behavioral experiments. There were no apparent differences in feeding between male and female mice under our experimental conditions, so we combined the data obtained from male and female mice. Mice used for experiments were purchased from The Jackson Laboratory. All mice were provided ad libitum access to food (LabDiet; 5008 Formulab Diet) and water unless otherwise noted. Before stereotaxic injections, mice were group housed three to five per cage. All chemicals were purchased from Sigma-Aldrich except clozapine- $N$-oxide $(\mathrm{CNO}$; water soluble), which was purchased from Enzo Life Sciences. For experiments requiring intraperitoneal injections, we diluted the stock of $\mathrm{CNO}$ in $200 \mu \mathrm{l}$ of saline. Injection into the abdomen was made at a $30^{\circ}$ angle and the shaft of the needle entered to a depth of $\sim 5 \mathrm{~mm}$.

\section{Viral vectors}

The viral vectors used in this study included: AAV vectors for Cre-dependent expression of ChR2 [AAV2-EF1a-DIO-hChR2 (H134R)-eYFP] or eYFP control virus (AAV2-EF1a-DIO-EYFP); trans-synaptic tracer virus (AAV2EF1a-IRES-WGA-Cre-mCherry); and Cre-dependent hM3Dq, hM4Di or mCherry (AAV2-hSyn-DIO-hM3D(Gq)-mCherry; AAV2-hSyn-DIO-
hM4D(Gi)-mCherry; AAV2-hSyn-DIO-mCherry). All viral vectors were provided by the University of North Carolina viral core facility and, on arrival, were aliquoted and stored at $-80^{\circ} \mathrm{C}$ before stereotaxic injections.

\section{Viral injections and optic fiber placement}

For surgical procedures, mice were anesthetized with a mixture of ketamine/zylazine $(60-75 \mathrm{mg} / \mathrm{kg} ; 10 \mathrm{mg} / \mathrm{kg}$; VET One) and placed in a stereotaxic injection rig (Harvard Apparatus). Stereotaxic injections were performed as described previously (Sweeney and Yang, 2015; Yang et al., 2015). Briefly, one or two small burr holes were made above the septum or the LH using a microprecision drill (Cell Point Scientific). A micromanipulator (Narishige) was used to deliver small controlled microinjections to either the septum (bregma $+0.4 \mathrm{~mm}$, midline $\pm 0.4 \mathrm{~mm}$, dorsal surface $-2.0 \mathrm{~mm}$ ) or the $\mathrm{LH}$ (bregma $-1.3 \mathrm{~mm}$, midline \pm 1.0 $\mathrm{mm}$, dorsal surface $-5.0 \mathrm{~mm}$ ) at a rate of $0.2 \mu \mathrm{min}^{-1}$. Injections were delivered either unilaterally or bilaterally, as described in the text and figure legends. Viral injection volumes were $200 \mathrm{nl}$ for septum and $300 \mathrm{nl}$ for $\mathrm{LH}$, respectively. Injection needles were left in place for $10 \mathrm{~min}$ after all injections to prevent leakage of virus to nontargeted brain regions. For trans-synaptic viral injections, two viral injections were performed simultaneously. The wheat germ agglutinin (WGA) fused to Cre recombinase (WGA-Cre) virus was injected into the LH together with injections of Cre-dependent virus in the septum. For in vivo photostimulation (PS) experiments, a ferrule-capped optical fiber $(1.25 \mathrm{~mm}$ Ceremic Ferrule; Thorlabs) was implanted $0.5 \mathrm{~mm}$ above either the septum (bregma +0.4 $\mathrm{mm}$, midline $-0.4 \mathrm{~mm}$, dorsal surface $-1.5 \mathrm{~mm}$ ) or the LH (bregma $-1.3 \mathrm{~mm}$, midline $-1.0 \mathrm{~mm}$, dorsal surface $-4.5 \mathrm{~mm}$ ). Cement (Dentsply) was used to secure the ferrule to the mouse skull. For postoperative care, subcutaneous administration of buprenorphine $(1 \mathrm{mg} / \mathrm{kg}$; VET One) was given twice daily for $3 \mathrm{~d}$ after surgery. Two weeks were allowed for recovery from surgical injections and the expressions of virally transduced proteins. All mice were single caged and handled for at least 1 week before the behavioral experiments.

\section{Feeding behavioral experiments}

Feeding assays with chemogenetic manipulations of septal or $\mathrm{LH}$ $\checkmark G A T$ neurons

Experiment 1.1: Chemogenetic manipulation of septal or LH $v$ GAT neurons (see Figs. 1, 6). To manipulate a subset of GABAergic neurons localized within the septal nucleus or LH selectively, we targeted Cre-dependent viral vectors encoding the stimulatory designer receptor exclusively activated by designer drugs (DREADD)-hM3Dq or inhibitory DREADDhM4Di into the septum or LH of vGAT-Cre transgenic mice that expressed Cre-recombinase in a subset GABAergic neurons expressing vesicular GABA transporter (see Fig. 1A). The DREADD-hM3Dq is an engineered G-protein-coupled receptor that activates Gq-signaling pathways selectively and activates neurons via peripheral CNO (Enzo Life Sciences) administration (Armbruster et al., 2007; Alexander et al., 2009). DREADD-hM4Di is an engineered G-protein-coupled receptor that activates $\mathrm{Gi}$ inhibitory signaling pathways selectively after $\mathrm{CNO}$ administration. Adult male and female mice 5-8 weeks of age were injected with Cre-recombinase-dependent AAV vectors that expressed hM3Dq, hM4Di, or mCherry, as described above. All behavioral experiments were performed in the animal's home cage. Experimental procedures were performed as described previously (Sweeney and Yang, 2015; Yang et al., 2015). Briefly, during feeding behavior experiments, food was replaced daily with $\sim 20 \mathrm{~g}$ of fresh standard chow diet. The food was the same as the diet provided to the mice ad libitum before the experiments. Food intake was calculated manually in the home cage at the indicated time points by briefly removing the food from the cages and measuring its weight. Food intake was measured after intraperitoneal injections of control saline $(0.9 \% ; 200 \mu \mathrm{l})$ or $\mathrm{CNO}(1 \mathrm{mg} / \mathrm{kg}$ for chemogenetic activation and $3 \mathrm{mg} / \mathrm{kg}$ for chemogenetic inactivation; prepared in sterile $0.9 \%$ saline; $200 \mu \mathrm{l}$ ). Cages were changed daily to prevent food debris from gathering at the bottom. During acute feeding behavior experiments, $\mathrm{CNO}$ and saline were administered on consecutive days in the following order: saline on days 1 and 2, $\mathrm{CNO}$ on day 3 , saline on day 4 , and $\mathrm{CNO}$ on day 5. Average food intake during saline and $\mathrm{CNO}$ conditions were cal- 
culated for each mouse and used in statistical analysis. To test for reductions in feeding, acute feeding measurements were performed during the early dark phase (8:30-9:00 P.M.) or after an overnight fast for mice expressing hM3Dq in septal vGAT neurons; light period (10:30-11:00 A.M.) feeding assays were performed for mice expressing hM4Di in septal vGAT neurons or hM3Dq in LH vGAT neurons to test for facilitation of food intake. For overnight fasting experiments, mice were fasted overnight from 6:00 P.M. until 9:00 A.M. the following morning. Fasting experiments were performed as described above except that control saline and $\mathrm{CNO}$ injections were administered in counterbalanced order, with half of the mice receiving $\mathrm{CNO}$ and half receiving saline (to prevent potential order effects due to fasting). Mice recovered for 1 week between all fasting experiments before beginning another round of fasting experiments. All behavioral experimental treatments (saline and $\mathrm{CNO}$ ) were repeated at least twice for each mouse.

Experiment 1.2: Chemogenetic activation of septal $v G A T$ neurons projecting to LH (see Fig. 4). Experimental procedures were performed as described above except that two viral injections were performed simultaneously for each mouse. WGA-Cre virus was injected into the LH together with injections of AAV vectors expressing Cre-dependent hM3Dq or Cre-dependent eYFP into the septum, as described in the text. After allowing 2 weeks for viral expression and recovery from surgical procedures, feeding behavior experiments were performed as described above.

\section{Optogenetic feeding behavior experiments}

\section{Experiment 2.1: Feeding assays with optogenetic stimulation of} septal vGAT neurons and their projections in LH (see Fig. 5)

AAV viral vectors expressing Cre-dependent ChR2 fused to eYFP or control eYFP were injected into the septum and optic cannulae were placed above the septum and $\mathrm{LH}$, respectively (detailed in the Results and Figure legends sections). As described in our previous study (Sweeney and Yang, 2015), fiber-optic cables (200 $\mu$ m diameter core; BFH48-200Multimode, numerical aperture 0.48 ; Thorlabs) were attached to implanted fiber-optic cannulae via ceramic mating sleeves (Thorlabs). After attachment of fiber-optic cables, mice were single housed in home cages and habituated to fiber-optic cables for $3 \mathrm{~d}$ before behavioral experiments. Ad libitum access to standard chow and water was made available at all times before and after optogenetic experiments. During PS, 30 or 60 min of light pulse trains ( $20 \mathrm{~Hz} ; 20$ pulses; repeated every $3 \mathrm{~s} ; 3 \mathrm{~ms}$ pulse) were applied using a waveform generator (3322A $20 \mathrm{MHz}$ function waveform generator; Agilent Technologies). Output from the waveform generator was coupled to a blue laser power ( $473 \mathrm{~nm}$; Altechna) to supply laser power to fiber-optic cables. Light power exiting the fiber-optic tip was calculated before experiments to be $15-20 \mathrm{~mW}$. At the start of optogenetic experiments, $2-3$ pellets of food $(6-8 \mathrm{~g})$ were placed on the bottom of each mouse's cage. Food intake was measured manually by carefully removing the food from the cage and obtaining its weight after either no PS or PS. The $30 \mathrm{~min}$ food intake was first measured without PS, followed by $30 \mathrm{~min}$ food intake with PS. Feeding behavioral experiments were performed during the dark cycle to take advantage of the high levels of basal food intake displayed by mice during this period (6:30-7:30 P.M.; lights turn off at 6:30 P.M.). Identical experiments were performed in mice expressing ChR2 and control eYFP fluorescent virus to control for potential effects due to light stimulation or treatment order. For mice in which PS was performed in both the septum and LH, stimulation was first applied to the septum as described above. Mice were then returned to their home cages for at least 1 week and a second round of identical PS experiments were performed while stimulating fibers in LH. All behavioral experiments were repeated at least twice per mouse. At the conclusion of all behavioral experiments, viral infection and cannula targeting were confirmed in all mice. Mice with inaccurate viral infection or cannula placement were excluded from statistical analysis.

\section{Experiment 2.2: Optogenetic stimulation of septal vGAT inputs} to $L H$ and chemogenetic stimulation of LH vGAT neurons (see Fig. 6C-E)

Viral injections and optogenetic experiments were performed as described above. To activate LH vGAT neurons during PS of septal vGAT inputs to LH, the proteins of ChR2 and hM3Dq were expressed in septum vGAT neurons and LH vGAT neurons, respectively. During feeding behavior experiments, intraperitoneal injections of $\mathrm{CNO}$ or saline were administered immediately before PS or no PS (as shown in Fig. 6D). Food intake was measured $1 \mathrm{~h}$ after intraperitoneal injections and during PS or no PS. Experiments were performed during the daytime (10:30-11:30 A.M.) to test for LH vGAT neuron-evoked feeding and were performed in a counterbalanced order to prevent potential order effects. For example, the first trial of experiments were performed every day in the following order: saline/PS, CNO/PS, saline/no PS, and CNO/no PS. After 1 week, we performed a second round of experiments in the opposite order: $\mathrm{CNO} /$ no PS, saline/no PS, CNO/PS, and saline/PS. Each treatment condition was repeated twice for each mouse and the average was calculated from the two trials for statistical analysis. For each mouse tested, the change in food intake (see Fig. $6 E$ ) was calculated by subtracting the average food intake for each mouse during saline conditions from the average food intake for each mouse during $\mathrm{CNO}$ conditions (CNO/ PS - saline/PS, and CNO/no PS - saline/no PS, respectively).

\section{Open-field behavioral testing}

Experiment 3: Open-field testing in DREADD-transduced mice (see Fig. 3)

Anxiety-related behavioral testing was performed following the procedures detailed in our previous studies (Sweeney and Yang, 2015; Sweeney et al., 2016). Briefly, open-field behavioral experiments were performed on vGAT-Cre mice transduced with hM4Di in septal vGAT neurons. On the day of open-field testing, mice were transferred to the open-field behavior room $30 \mathrm{~min}$ before starting experiments. The open-field arena consisted of a brightly lit, $500 \mathrm{~mm}^{2}$ arena in the center of the behavioral room. All mice were administered intraperitoneal injections of $\mathrm{CNO}$ or control saline $10 \mathrm{~min}$ before being placed in the open-field arena. Mice were then placed in the center of the open field and allowed to explore freely for $10 \mathrm{~min}$. Exploratory activity was tracked and scored by using ANY-maze software (Stoelting). Between trials, the arena was cleaned with $70 \%$ alcohol. Experiments were performed in a counterbalanced order such that half of the mice received saline on experimental day 1 and the other half received CNO. One week later, open-field experiments were repeated with the opposite conditions such that mice that received saline during the first trial received $\mathrm{CNO}$ and those that received $\mathrm{CNO}$ received saline. Total distance traveled, speed, time in the center of the open field, and distance traveled in the center of the open field for each mouse in control saline and $\mathrm{CNO}$ conditions, respectively, were used for statistical comparisons.

\section{Electrophysiology and circuit mapping}

Experiment 4: ChR2-assisted septum to LH circuit mapping and electrophysiological conformation of chemo/optogenetic

manipulation of neuron activity (see Figs. 2, 5J,K)

For chemo/optogenetic manipulation of neural activity, experiments were performed on mice transduced with ChR2 or DREADDs (see "Viral injection" section) in septal vGAT neurons. Acute coronal sections that included the septum or LH were prepared from the transduced mice with ChR2, hM3Dq, hM4Di, or control fluorescent protein, respectively, in septal or LH neurons (detailed in the Results section) following the procedures reported in our previous studies (Qi and Yang, 2015; Sweeney and Yang, 2015; Yang et al., 2015). Briefly, mice were deeply anesthetized with isoflurane and decapitated. Mouse brains were dissected rapidly and placed in ice-cold oxygenated $\left(95 \% \mathrm{O}_{2}\right.$ and $\left.5 \% \mathrm{CO}_{2}\right)$ solution containing the following (in mM): 110 choline chloride, $2.5 \mathrm{KCl}, 1.25 \mathrm{NaH}_{2}$ $\mathrm{PO}_{4}, 2 \mathrm{CaCl}$, $7 \mathrm{MgSO}_{4} 25$ D-glucose, $3.1 \mathrm{Na}$-pyruvate, and $11.6 \mathrm{Na}-\mathrm{L}$ ascorbate, $\mathrm{pH}$ 7.3. Coronal brain slices ( $260 \mu \mathrm{m}$ thickness) were cut with a vibratome (Vibratome 1000S), maintained in an incubation chamber at $34^{\circ} \mathrm{C}$ for $30 \mathrm{~min}$, and then brought to room temperature until being transferred to a recording chamber. During experiments, an individual slice was transferred to a submersion-recording chamber and continuously perfused with recording solution containing the following (in $\mathrm{mM}$ ): $119 \mathrm{NaCl}, 25 \mathrm{NaHCO}_{3}, 11 \mathrm{D}$-glucose, $2.5 \mathrm{KCl}, 1.25 \mathrm{MgCl}_{2}, 2 \mathrm{CaCl}_{2}$, and $1.25 \mathrm{NaH}_{2} \mathrm{PO}_{4}$, aerated with $95 \% \mathrm{O}_{2} / 5 \% \mathrm{CO}_{2}(\sim 1-2 \mathrm{ml} / \mathrm{min}$ at room 

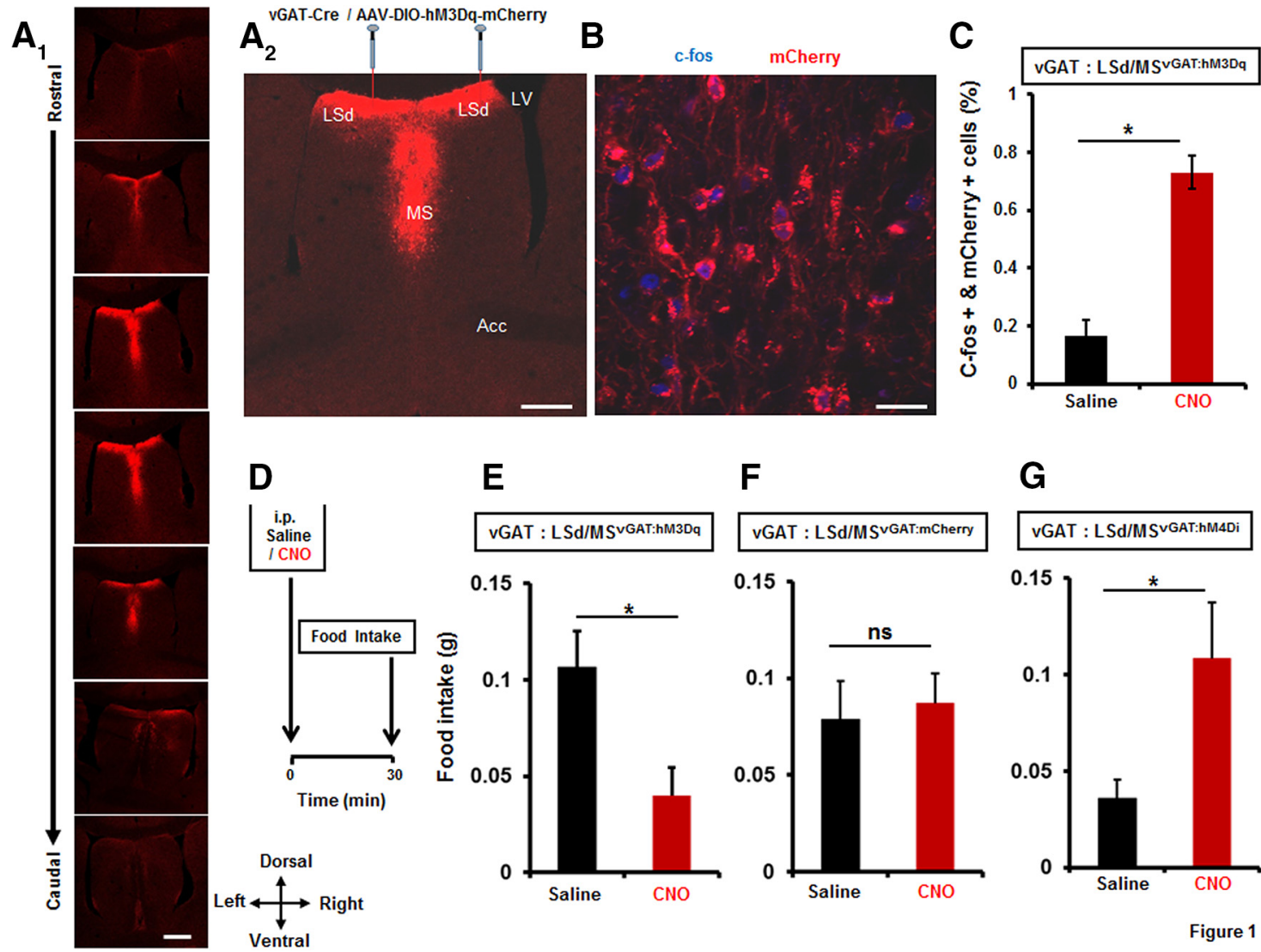

$\mathbf{F}$

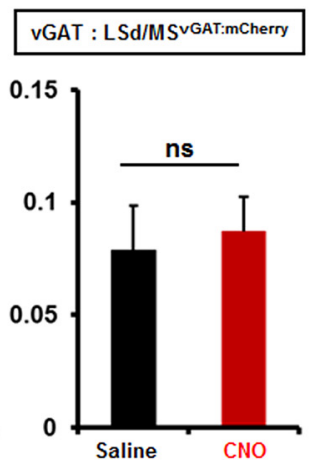

G

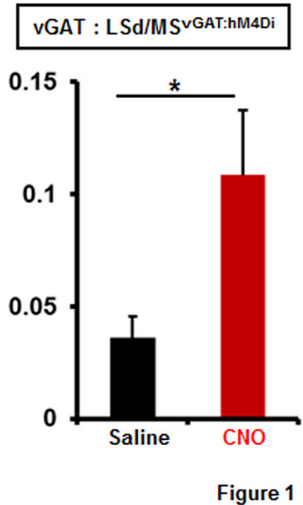

Figure 1. Anorexigenic effects of septal vGAT neurons on food intake. A1, Sample images of viral infections throughout the rostral-caudal axis of the septal nucleus in a mouse transfected with hM3Dq-mCherry in the septum in a vGAT-Cre mouse. A2, Representative image showing bilateral Cre-dependent transduction of hM3Dq-mCherry in LSd/MS vGAT neurons in a vGAT-Cre mouse. $B$, Sample image showing overlap between hM3Dq-mCherry positive LSd/MS vGAT neurons and c-fos signals. Intraperitoneal injections of CNO $(n=2$ mice) or vehicle saline $(n=2$ mice) were administered 30 min before perfusions to activate vGAT neurons selectively. C, Quantification of the percentage of c-fos-positive LSd/MS vGAT neurons that coexpress mCherry after intraperitoneal injections of saline or CNO. CNO injections increased the percentage of c-fos-positive cells also expressing mCherry significantly. D, Schematic outlining feeding behavior protocol. Ad libitum fed mice were administered intraperitoneal injections of CNO or saline and ad libitum access food intake was accessed 30 min after intraperitoneal injections. E, CNO administration reduced food intake in DREADD-hM3Dq-transduced mice ( $n=6$ mice). $\boldsymbol{F}$, No significant differences in food intake were detected between saline and CNO treatments in mice transduced with the control fluorescent protein $\mathrm{mCherry}(n=8$ mice). G, CNO administration increased food intake in DREADD-hM4Di-transduced mice ( $n=6$ mice). Data are shown as mean \pm SEM. Experiments were repeated at least two times per mouse and average values were calculated for each mouse for saline and CNO treatment conditions. LSd, Dorsal lateral septum; LV, lateral ventricle; MS, medial septum; Acc, anterior commissure. Scale bars: $\boldsymbol{A} \mathbf{1}, \boldsymbol{A 2}, 200 \mu \mathrm{m} ; \boldsymbol{B}, 20 \mu \mathrm{m} .{ }^{*} p<0.05$, n.s. (not significant).

temperature). Recordings were made at fluorescently labeled septal or LH neurons identified using a Nikon microscope.

Whole-cell patch-clamp recordings were made in either current- or voltage-clamp configuration while holding the neurons at $-60 \mathrm{mV}$ throughout the experiment using an Axo-patch $700 \mathrm{~B}$ amplifier (pClamp 10.0 software; Molecular Devices). The recording electrodes had tip resistances of $\sim 3-5 \mathrm{M} \Omega$. Recording pipettes were routinely filled with a solution containing the following (in $\mathrm{mM}$ ): $125 \mathrm{~K}$-gluconate, $15 \mathrm{KCl}, 10$ HEPES, $8 \mathrm{NaCl}$, $4 \mathrm{Mg}$-ATP, $0.3 \mathrm{Na}$-GTP, $10 \mathrm{Na}_{2}$-phosphocreatine, and 2 EGTA, pH 7.30. Synaptic responses or action potential firing rates were digitized at $10 \mathrm{kHz}$. Neurons with series resistances $<30 \mathrm{M} \Omega$ were used for recordings. For optogenetic stimulation, the postsynaptic currents or neural firing rates were recorded while shining blue light on the surface of brain slices using an optic fiber connected to a blue laser power (CrystaLaser $473 \mathrm{~nm}$ ) delivering light pulses ranging from 0.1 to $1 \mathrm{~mW}$ at the specimen. Light pulse duration (1-3 ms) was controlled with pCLAMP 10 software (Molecular Devices). For DREADD-based manipulations of neuronal firing rates, whole-cell current-clamp mode was used for recording neuronal firing rates with a holding potential of $-60 \mathrm{mV}$. For ChR2-based activation of septal neurons, loose-seal cell-attached recordings (seal resistance, 20-70 $\mathrm{M} \Omega$; artificial cerebrospinal fluid (aCSF) internal) were made on ChR2-transduced septum neurons in voltageclamp mode with the holding current maintained at zero throughout the entire experiment.

\section{Immunofluorescence and imaging}

After all the behavioral experiments, mice were anesthetized with an overdose of ketamine/zylazine (60-75 and $10 \mathrm{mg} / \mathrm{kg}$, respectively; VET One) before cardiac perfusions. Mice were perfused with $0.1 \mathrm{M}$ PBS, followed by $4 \%$ paraformaldehyde (PFA) in $0.1 \mathrm{M}$ PBS. After perfusion, mouse brains were removed and fixed overnight in 4\% PFA. Tissue was subsequently immersed for $24 \mathrm{~h}$ each in $10 \%, 20 \%$, and $30 \%$ sucrose solutions (prepared in $0.1 \mathrm{M}$ PBS). Brain sections $(40 \mu \mathrm{m})$ were prepared using a cryostat (Leico Microsystems) and mounted onto glass slides for conformation of viral infection and cannula placement. For c-fos immunostaining, intraperitoneal injections of $\mathrm{CNO}$ or control saline were administered $30 \mathrm{~min}$ before perfusion. Sections were washed 3 times in 0.1 M PBS and blocked in 2\% bovine serum albumin (084K8926; SigmaAldrich) in $0.1 \mathrm{M}$ PBS and $0.1 \%$ Tween 20 for $2 \mathrm{~h}$. Primary antibody (rabbit anti-Fos; 1:150; Santa Cruz Biotechnology) incubated in blocking buffer was added overnight. Sections were then washed 3 times and secondary antibody (donkey anti-rabbit 680, 1:500; Life Technologies) was added in blocking buffer for $2 \mathrm{~h}$. Sections were again washed three times and mounted onto glass slides. Slides were stored at $4^{\circ} \mathrm{C}$ before image acquisition. To quantify total c-fos levels, random sections were sampled and imaged for $\mathrm{c}$-fos reactivity in response to intraperitoneal CNO or saline injections. Overlap between c-fos- and mCherry-positive neurons was determined by first quantifying the number of c-fos-positive cells in 
A

LSd/MS vGAT:hM3Dq

CNO $(5 \mu M)$

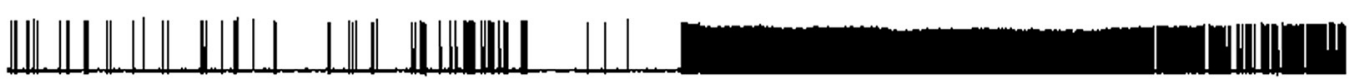

B
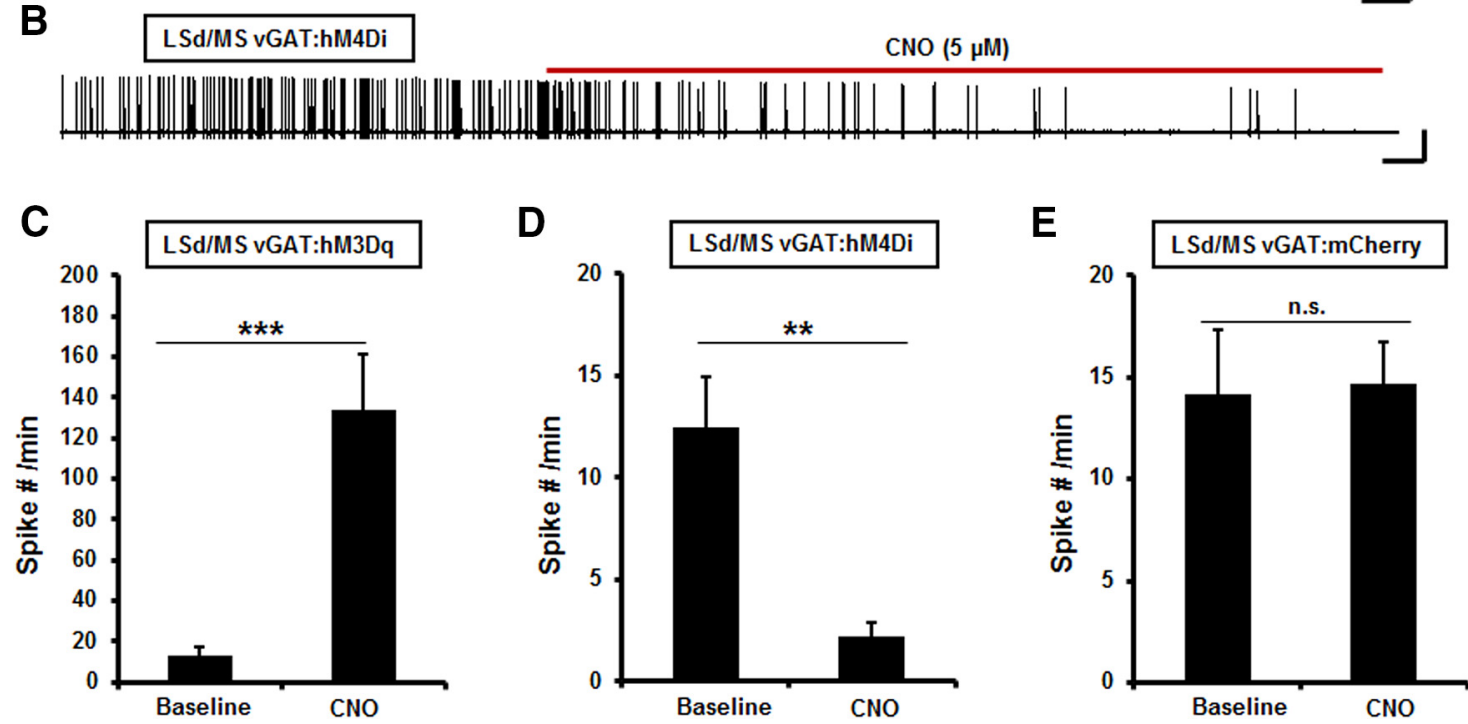

Figure 2. DREADD-based activation and inactivation of septal vGAT neurons. $A$, Sample trace showing that the addition of $\mathrm{CNO}$ to an acute brain slice from a mouse transduced with $\mathrm{hM} 3 \mathrm{Dq}$ in LSd/MS increased the firing rate of septal vGAT neurons significantly compared with before the addition of CNO. B, Sample trace of whole-cell recording of action potentials at one LSd/MS vGAT neuron transduced with hM4Di in an acute brain slice of a vGAT-Cre mouse. CNO decreased the firing rates significantly compared with before the addition of CNO. C, Grouped data from the experiments performed in $\boldsymbol{A}$ in septal vGAT-hM3Dq transduced mice $(n=9)$. $\boldsymbol{D}$, Grouped data from the experiments performed in $\boldsymbol{B}$ in septal vGAT-hM4Di-transduced mice $(n=7)$. $\boldsymbol{E}$, Grouped data from experiments performed in septal vGAT-mCherry-transduced mice $(n=7)$. Data are shown as mean \pm SEM. Current whole-cell patch-clamp recordings were made at hM3Dq-, hM4Di-, or $\mathrm{mCherry}$-transduced LSd/MS vGAT neurons with a holding potential of $-60 \mathrm{mV}$. Scale bar, $50 \mathrm{mV}$ and $30 \mathrm{~s}$. ${ }^{* *} p<0.01,{ }^{* * *} p<0.001$, n.s. (not significant).

the septum and then determining the percentage of these cells that overlapped with mCherry signal. For each mouse, c-fos signals were quantified from four to six random sections and the average number of ${\mathrm{c}-\mathrm{fos}^{+}}^{+}$ mCherry ${ }^{+}$neurons from the counted sections for each mouse was used for statistical analysis.

\section{Data analysis}

Mice were assigned randomly to experimental (DREADD or ChR2 transduced) or control (control florescent protein transduced) groups before viral injections and behavioral experiments. After post hoc histological conformation of viral transfection and cannula placements, all mice with inaccurate viral infections or cannula placements were excluded from behavior experiments. All experiments were repeated at least twice for each mouse and an average value was calculated for each mouse for statistical analysis. Data that were normally distributed were analyzed with two-tailed paired or unpaired Student's $t$ test to compare group data when only two conditions were being compared between the same or different mice, respectively. Data that did not display a normal distribution were analyzed with a Wilcoxon matched-pairs rank test or a Mann-Whitney test for the same or different mice, respectively. Repeated-measures ANOVA with the within-subjects factors of injection condition (saline vs CNO) and time $(0-1,1-2$, or $2-5 \mathrm{~h}$ ) were used to analyze the data shown in Figure 4, D and E. Mixedfactorial ANOVA with the between-subjects factor of viral injection type (eYFP vs hM3Dq) and the within-subjects factor of time was used to analyze the data shown in Figure $4 F$. Sidak's post hoc test was used to determine significant effects at the various time-segments after the detection of a significant main effect. All data analysis was performed using Prism version 6.0 (GraphPad Software).

\section{Results}

Activation of septal vGAT neurons reduces food intake

To examine the influential effects of septal vGAT neurons on food intake, we targeted a Cre-dependent viral vector encoding the stimulatory DREADD-hM3Dq into the septum of vGAT-Cre transgenic mice (Fig. 1A). After viral transduction of the Credependent DREADD-hM3Dq, we observed dense vGAT neuronal expression in the dorsal region of lateral septum (LSd) and the medial septum (MS) (hereafter referred to as LSd/MS vGAT neurons; Fig. 1A). As expected, intraperitoneal injections of the selective DREADD agonist CNO increased the neuronal activity of LSd/MS vGAT neurons transduced with hM3Dq, as indicated by increased neuronal c-fos levels (Fig. $1 B, C ; t_{(2)}=7.24, p=0.02$, Student's unpaired $t$ test; $n=8-12$ sections $/ 2$ mice for the saline and $\mathrm{CNO}$ groups, respectively). Further in vitro patch-clamp recordings confirmed that $\mathrm{CNO}$ activates LSd/MS neurons transduced with the stimulatory hM3Dq potently compared with the basal neural firing level (Fig. $2 A, C ; t_{(16)}=4.30, p=0.0006$; Student's unpaired $t$ test; $n=9$ neurons from 3 mice). To determine whether these neurons regulate food intake, we next performed feeding assays after intraperitoneal injections of $\mathrm{CNO}$ or saline. Interestingly, we observed that DREADD-based activation of LSd/MS vGAT neurons reduced feeding during the dark period of the rodent light cycle, when mice usually consume food actively (Fig. $1 E ; t_{(5)}=3.42, p=0.02 ; n=6$ mice; Student's paired $t$ test). To further explore the role of these neurons when mice are more motivated to consume food, we performed similar experiments in mice after an overnight fast and observed a similar trend toward reduced fasting-evoked feeding (saline: $0.93 \pm 0.04, \mathrm{CNO}: 0.81 \pm 0.07 ; t_{(5)}=2.54, p=0.05 ; n=6$ mice; Student's paired $t$ test). CNO administration had no apparent effects on food intake in mice transduced with control mCherry, indicating that $\mathrm{CNO}$ did not exert nonspecific effects on food intake (Fig. $1 F ; t_{(7)}=0.27, p=0.79 ; n=8$ mice; Student's paired $t$ test). 
The aforementioned gain-of-function experiments indicated that activation of LSd/MS vGAT neurons is sufficient to reduce food intake (Fig. 1E); however, they do not reveal the significance of these neurons during normal feeding conditions or whether these neurons exert tonic inhibition of food intake. We thus performed loss-of-function experiments by transducing LSd/MS vGAT neurons with the inhibitory DREADD-hM4Di. Consistent with the well described inhibitory role of hM4Di (Armbruster et al., 2007; Alexander et al., 2009; Stachniak et al., 2014), in vitro patch-clamp recordings confirmed that $\mathrm{CNO}$ reduces the firing rate of LSd/MS vGAT neurons transduced with the inhibitory DREADD-hM4Di (Fig. $2 B, D ; t_{(12)}=3.37, p=0.006$; Student's unpaired $t$ test; $n=7$ neurons from 2 mice). In addition, we observed that DREADD-based inactivation of these neurons increased food intake during the light cycle, when mice usually consume less food (Fig. $1 G ; t_{(5)}=2.96, p=0.03$; Student's paired $t$ test; $n=6$ mice).

Because alterations in basal anxiety levels or locomotion may effect feeding behavior, we next investigated whether LSd/MS vGAT neural regulation of food intake was secondary to the potential changes in anxiety or locomotion. To test this possibility, we performed open-field exploration tests in vGAT-Cre mice transduced with the DREADD-hM4Di in LSd/MS vGAT neurons. Similarly to a previous report, we did not observe apparent changes in basal anxiety levels during chemogenetic inactivation of LSd/MS vGAT neurons (Anthony et al., 2014). In particular, no significant differences were detected between saline and $\mathrm{CNO}$ treated mice in time spent in the center (Fig. $3 C ; t_{(8)}=0.01, p=$ 0.99; Student's paired $t$ test; $n=9$ mice) or distance traveled in the center (Fig. $3 D ; t_{(8)}=-1.09, p=0.30$; Student's paired $t$ test; $n=9$ mice). Whereas DREADD-based inactivation of LSd/MS vGAT neurons increased food intake (Fig. $1 G$ ), locomotion was not altered, as measured by total distance traveled (Fig. 3A; $t_{(8)}=-0.06, p=0.95$; Student's paired $t$ test; $n=9$ mice) and average speed (Fig. $3 B ; t_{(8)}=-0.13, p=0.90$; Student's paired $t$ test; $n=9$ mice). These findings suggest that LSd/MS vGAT neurons are not significantly involved in anxiety or locomotion under basal conditions, although we cannot rule out more subtle roles for these neurons in anxiety, locomotion, or other behaviors related to feeding.

\section{Activation of septal neurons projecting to $\mathrm{LH}$ reduces food intake}

We next sought to identify the projection target(s) of septal neurons that is responsible for septal neural reductions in food intake. Previous studies have established that multiple septal subregions, including LSd and MS, project to the LH (Risold and Swanson, 1997; Sartor and Aston-Jones, 2012). Based on the well established role of $\mathrm{LH}$ in the control of feeding behavior (Anand et al., 1951; Grossman et al., 1978; Stricker et al., 1978; Grossman et al., 1982; Berthoud and Münzberg, 2011; Brown et al., 2015; Jennings et al., 2015; Nieh et al., 2015; Wu et al., 2015; Stamatakis et al., 2016), we investigated whether septal projections to LH regulate food intake. To determine whether septal neurons project to $\mathrm{LH}$ and to investigate the role of these projections in the control of food intake, we used a "retro-DREADD" approach described previously (Gradinaru et al., 2010; Xu and Südhof, 2013; Sweeney and Yang, 2015). The trans-synaptic tracer WGA-Cre was injected into the LH simultaneously with a second injection of Cre-dependent hM3Dq into septum (Fig. $4 A-C$ ), allowing for the selective labeling and activation of septal neurons anatomically connected with the LH. After viral transduction, we observed sparse labeling of hM3Dq-mCherry soma
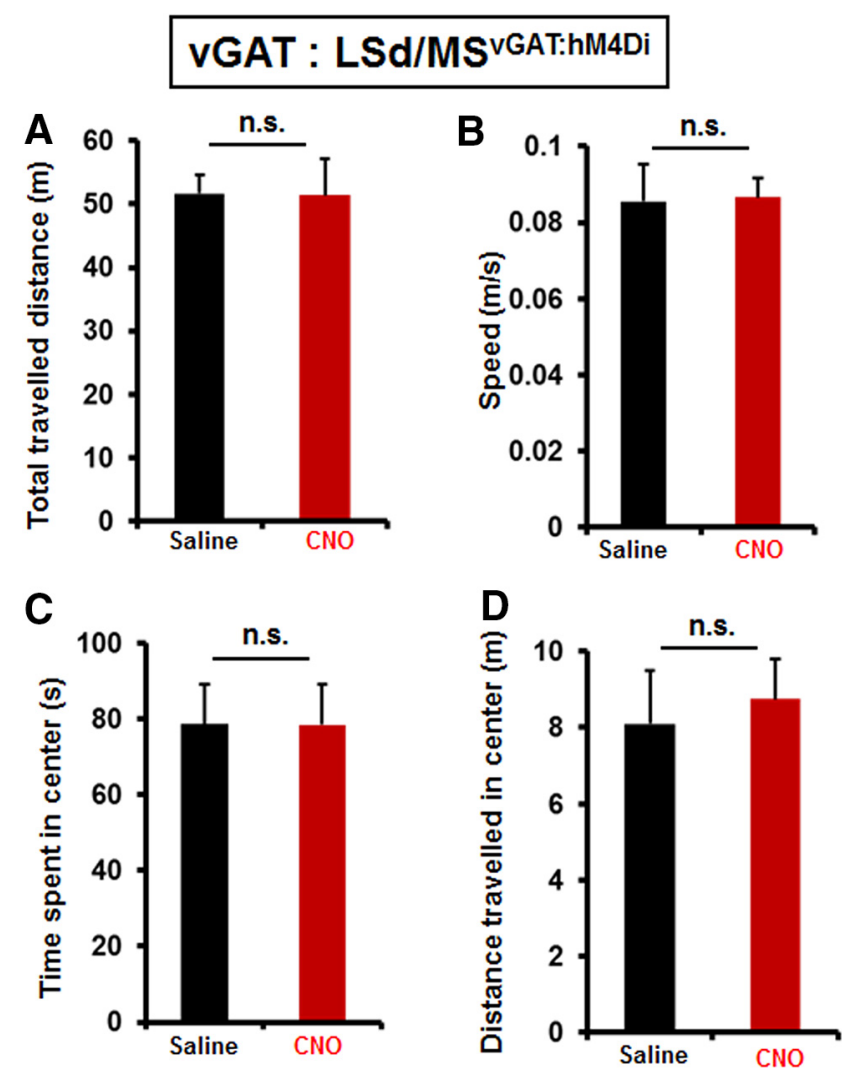

Figure 3. DREADD-based manipulation of septal vGAT neurons does not affect anxiety or locomotion. A, Grouped behavioral data showing total distance traveled during $10 \mathrm{~min}$ in the open field in vGAT-Cre mice transduced with hM4Di in septal vGAT neurons. No significant difference was detected between saline and CNO treatment conditions in total distance traveled during $10 \mathrm{~min}$ of open-field exploration. $\boldsymbol{B}$, Grouped behavioral data of the average speed in the open field after saline or CNO injections. No significant differences were detected between saline and CNO treatments in DREADD-hM4Di transduced mice. C, D, Time in center and distance in center after CNO and saline treatments in DREADD-hM4Di-transduced mice. No significant differences were detected in time spent in center or distance traveled in center between the two treatment groups. $n=9$ mice for all panels; n.s. (not significant).

in the septum (Fig. 4C). Chemogenetic activation of septal neurons connected to $\mathrm{LH}$ led to a reduction in food intake (Fig. $4 D$; main effect of CNO treatment, $F_{(1,6)}=25.29, p=0.002$; two-way repeated-measures ANOVA with within-subjects factors of treatment and time segment; $n=7$ mice). To control for potential nonspecific effects of $\mathrm{CNO}$, we performed similar experiments in mice transfected with WGA-Cre in LH and control virus in septum. Consistently, food intake was not reduced after CNO treatment in mice transduced with control virus in septum (Fig. 4E; main effect of CNO treatment, $F_{(1,5)}=3.3, p=0.13$; two-way repeated-measures ANOVA with within-subjects factors of treatment and time segment; $n=6$ mice). We also observed that food intake was significantly reduced in hM3Dq-transduced mice treated with $\mathrm{CNO}$ compared with control eYFP-transduced mice treated with $\mathrm{CNO}$ (Fig. $4 F$; main effect of virus injection; $F_{(1,11)}=$ 29.17, $p<0.001$; mixed-factorial ANOVA with within-subjects factor of time segment and between-subjects factor of virus injection type; $n=6$ mice for eYFP group and $n=7$ mice for hM3Dq group). Post hoc analysis indicated that food intake was reduced in hM3Dq-injected mice from 1 to $2 \mathrm{~h}$ after injection $(p=0.009)$ and $2-5 \mathrm{~h}$ after injection $(p=0.01)$ and trended toward a reduction in food intake from 0 to $1 \mathrm{~h}$ after injection $(p=0.06)$. Although WGA may label polysynaptically connected neurons in both the anterograde and retrograde direction, retro- 

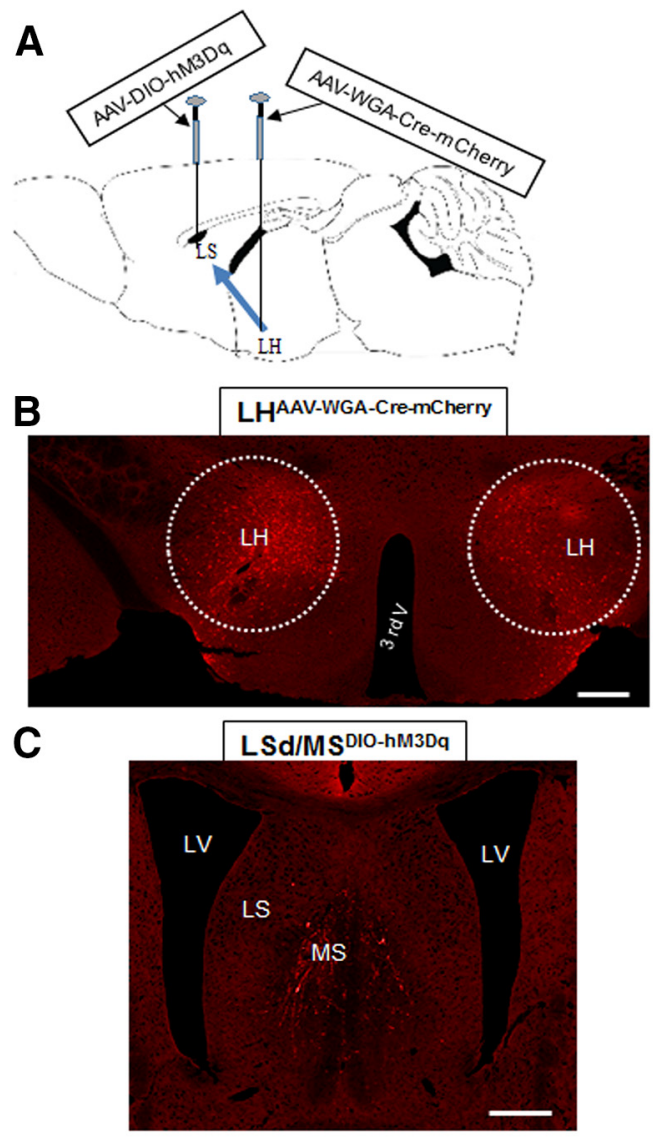

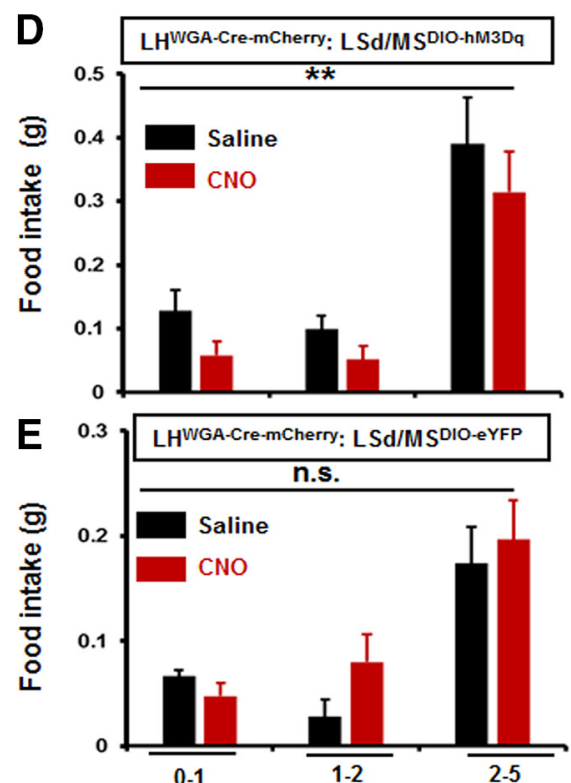

Intervals post saline or CNO injections (hr)

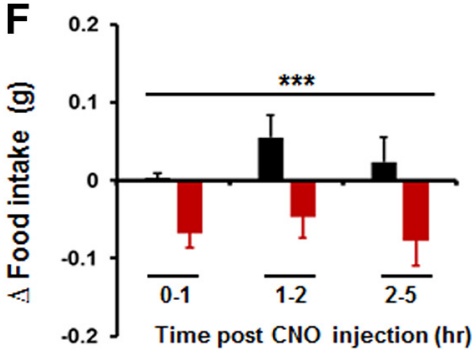

Figure 4. Selective activation of $\mathrm{LH}$-projecting septal neurons reduces feeding. $\boldsymbol{A}$, Experimental design to express hM3Dq selectively in septal neurons anatomically connected with $\mathrm{LH}$. The trans-synaptic tracer virus AAV-WGA-Cre-mCherry was bilaterally injected into the LH together with bilateral injections of the Cre-dependent DREADD-hM3Dq into septum. The trans-synaptic tracer virus transports Cre-recombinase to anatomically connected cell populations, allowing for Cre-dependent viral infection only in neurons connected with LH. B, C, Sample images showing WGA-Cre-mCherry expression in the LH (B) and Cre-dependent hM3Dq expression in the septum ( $(\boldsymbol{C}$. D. Feeding behavior experiments showing that intraperitoneal injections of $C$ NO reduce feeding in hM3Dq-transduced mice relative to saline treatment ( $n=7$ mice per group). $\boldsymbol{E}$, No significant difference was detected between saline and CNO treatments in mice injected with control eYFP virus in septum ( $n=6$ mice per group). $\boldsymbol{F}$, Change in food intake (relative to saline injection condition) in mice transduced with hM3Dq $(n=7)$ or eYFP $(n=6)$ in septal vGAT neurons. A significant main effect of viral injection type was detected, showing that mice injected with hM3Dq ate significantly less than mice injected with eYFP control virus in response to CNO injections. Significant differences in food intake were also detected between 1 and $2 \mathrm{~h}$ and $2-5 \mathrm{~h}$ after injection, with a trend toward reduced food intake from $0 \mathrm{to} 1 \mathrm{~h}$ after injection. Each mouse tested was injected with saline or CNO and average food intake measurements for both conditions were calculated at the indicated time points. The differences in food intake at each time point for each mouse between saline and CNO conditions were used for statistical analysis. Data are shown as mean \pm SEM. $3 \mathrm{rdV}$, third ventricle; LV, lateral ventricle; LS, lateral septum; MS, medial septum. Scale bars: $\boldsymbol{B}, 400 \mu \mathrm{m} ; \mathrm{C}, 500$ $\mu \mathrm{m} .{ }^{*} p<0.05,{ }^{* *} p<0.01,{ }^{* * *} p<0.001$.

DREADD experiments suggest that activation of septal projections in $\mathrm{LH}$ reduce feeding. We thus next sought to perform cell-type-specific optogenetic experiments to determine the role of this putative neural circuit in the control of food intake.

\section{Activation of septal vGAT projections in $\mathrm{LH}$ reduces food intake}

Because chemogenetic activation of LSd/MS vGAT neurons (Fig. $1 E$ ) or the LH-projecting septal neurons reduced food intake (Fig. 4), we predicted that LSd/MS vGAT neurons constitute a major septal projection pathway to the $\mathrm{LH}$, which is supported by previous reports that GABAergic neurons are the most abundant neurons within the septum (Risold and Swanson, 1997). To stimulate LSd/MS vGAT neuronal projections in the LH selectively, we expressed Cre-dependent ChR2 in LSd/MS vGAT neurons and inserted an optic fiber above the LH in vGAT-Cre mice (Fig. $5 A-C$ ). Consistent with our chemogenetic data (Fig. 1E), we observed that in vivo PS of LSd/MS vGAT neuronal soma markedly reduced food intake (Fig. $5 E ; t_{(4)}=3.73, p=0.02$; Student's paired $t$ test; $\mathrm{n}=5$ mice). In vitro current-clamp recordings con- firmed that PS ( $20 \mathrm{~Hz}$ for $1 \mathrm{~s}$, repeated every $3 \mathrm{~s}$ ) reliably evoked action potentials in ChR2-transduced LSd/MS vGAT neurons (Fig. 5J), consistent with a previous report (Aponte et al., 2011). Furthermore, in vivo optogenetic stimulation of LSd/MS vGAT projections in $\mathrm{LH}$ led to a reduction in food intake, indicating that LSd/MS vGAT projections to the LH contribute to LSd/MSbased appetite suppression (Fig. $5 F ; Z=-43, p=0.03$; Wilcoxon signed-rank test; $n=10$ mice). To exclude the possibility of nonspecific effects potentially caused by in vivo PS, we performed similar experiments in mice transduced with the control fluorescent protein eYFP in LSd/MS vGAT neurons and did not observe a significant effect on food intake after PS (Fig. $5 G ; t_{(9)}=$ 1.27, $p=0.24$; Student's paired $t$ test; $n=10$ mice). To further control for the potential effects of PS on food intake, we compared the change in food intake (i.e., food intake during PS minus food intake before PS) for each mouse after PS in ChR2- and eYFP-transduced mice. Importantly, we found that optogenetic stimulation of vGAT soma in septum (Fig. $5 H$; $t_{(12)}=3.32, p=$ 0.006; Student's unpaired $t$ test; $n=9$ mice for the eYFP group and $n=5$ mice for the ChR2 group, respectively) and neuronal fibers in 
A

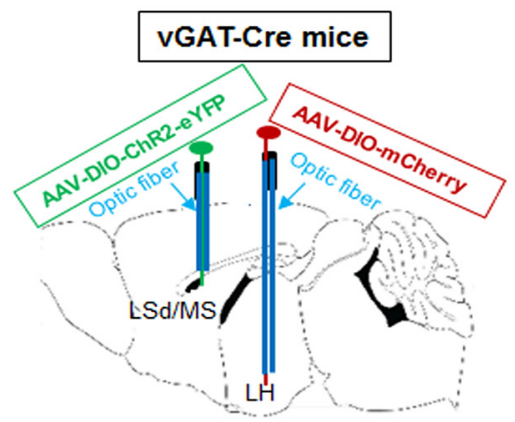

D

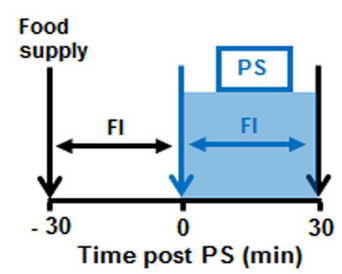

B
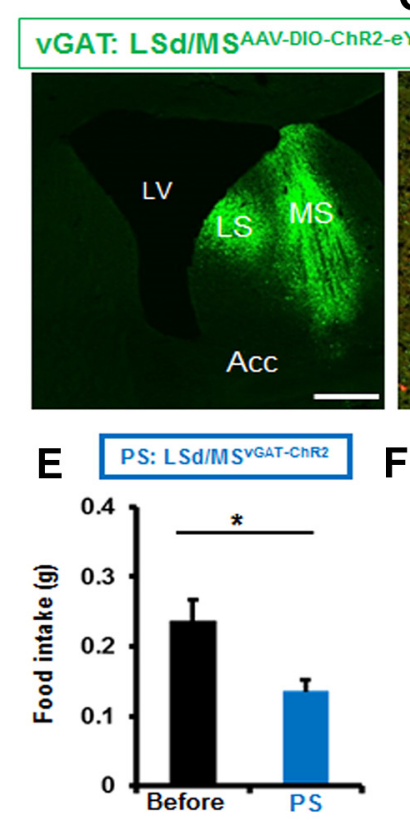

C
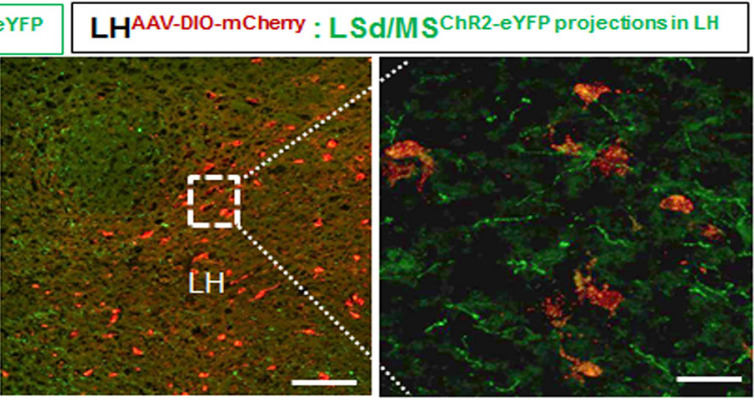

$\mathbf{F}$
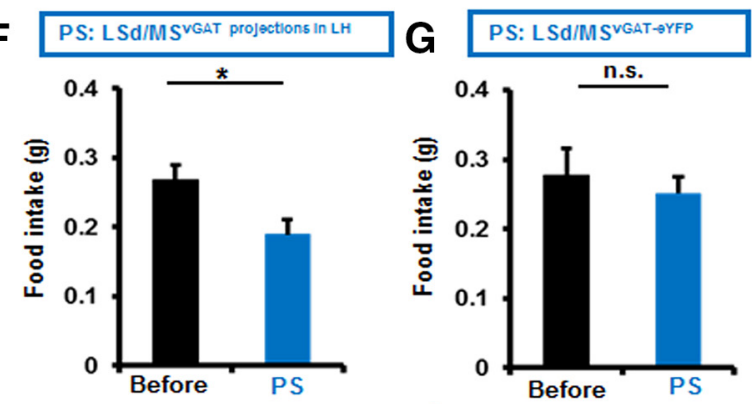
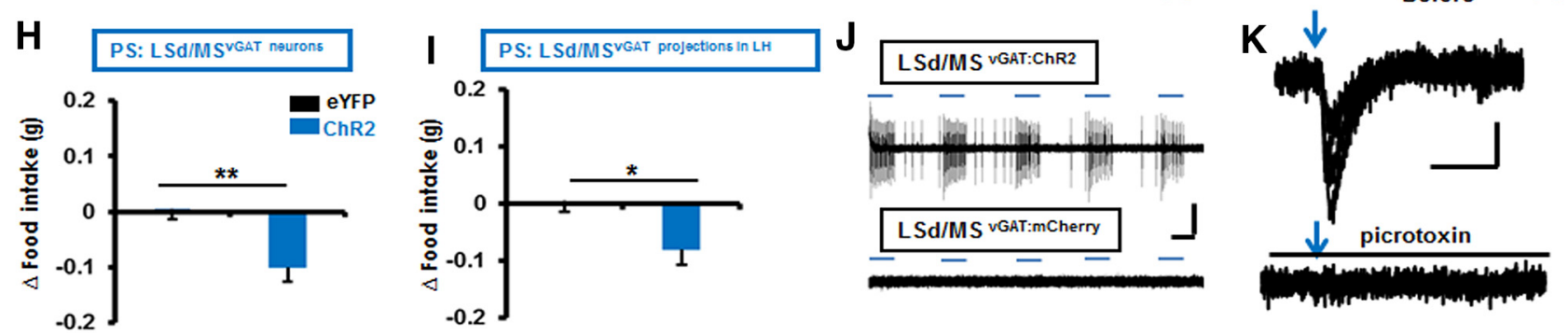

Figure 5. ChR2-assisted dissection of an inhibitory septal-hypothalamic feeding circuit. $A$, Strategy to express channelrhodopsin (ChR2) in LSd/MS vGAT neurons and insert fiber-optic cannula above LSd/MS or LH. Cre-dependent viral injections of ChR2 and the control fluorescent protein mCherry were delivered into LSd/MS and LH, respectively, to photostimulate LSd/MS vGAT neurons or their projections in LH and to label vGAT neurons in LH. Fiber-optic cannulas were inserted above both LSd/MS and the LH to stimulate LSd/MS vGAT neurons or LSd/MS projections selectively in the LH. B, Representative image showing viral expression of Cre-dependent ChR2 in the LSd/MS of a vGAT-Cre mouse. C, Images showing LSd/MS neuronal projections labeled with ChR2-eYFP (green) in the LH with overlapping LH vGAT neurons labeled with mCherry (red). D, Experimental design for optogenetic feeding behavior experiments. Food intake was measured at 30 min increments before and during PS. $\boldsymbol{E}$, PS of LSd/MS neurons reduced food intake ( $n=5$ mice). $\boldsymbol{F}$, PS of LSd/MS projections in the LH reduced food intake ( $n=10$ mice per group). $\boldsymbol{G}$, No significant changes in feeding were detected in mice injected with control eYFP-expressing vectors $(n=10)$. $\boldsymbol{H}$, Change in food intake during PS of septum (relative to before PS) for mice expressing eYFP in septum ( $n=9$ mice) or ChR2 in septum ( $n=5$ mice). A significant difference in food intake was detected between eYFP- and ChR2-transduced mice, indicating that PS of septal vGAT neurons reduced feeding relative to eYFP control conditions. Change in food intake was calculated by subtracting the average amount of food consumed before PS from the average amount of food consumed during PS for each mouse to obtain a change score for every mouse tested. All change scores for all mice were averaged for statistical analysis. I, Change in food intake during PS of septal projections in LH in mice transduced with ChR2 ( $n=10$ mice) or control eYFP virus $(n=10$ mice). PS of septal vGAT fibers expressing ChR2 in LH reduced food intake compared with PS of eYFP fibers in LH. J, Sample traces of PS-evoked action potential firing of septal vGAT neurons transduced with either ChR2 (top trace; $n=8$ ) or control eYFP (bottom trace; $n=6$ ); blue lines represent the onset and offset of PS (20 Hz for $1 \mathrm{~s}$, repeated every $3 \mathrm{~s}$ ). $\boldsymbol{K}$, ChR2-assisted circuit mapping. IPSCs were recorded at LH vGAT neurons ( 5 of 25 recorded neurons) while photostimulating ChR2-expressing LSd/MS VGAT projections in the LH in the presence of TTX and 4-AP. IPSCs were diminished in the presence of the GABA $A_{A}$ receptor antagonist picrotoxin (100 $\mu$ M). Data are shown as mean \pm SEM. Scale bars: B, 200; C, left, $100 \mu \mathrm{m} ; \boldsymbol{C}$, right, $20 \mu \mathrm{m} ; \boldsymbol{J}, 40 \mathrm{pA}$ and $1 \mathrm{~s} ; \boldsymbol{K} .4 \mathrm{pA}$ and $50 \mathrm{~ms}^{*}{ }^{*} p<0.05,{ }^{* *} p<0.01$, n.s. (not significant).

LH (Fig. 5I; $U=19, p=0.03$; Mann-Whitney test; $n=9$ mice for the eYFP group and $n=10$ mice for the ChR2 group, respectively) significantly reduced food intake in ChR2-transduced mice compared with eYFP-transduced mice.

\section{Septal vGAT neurons project to LH vGAT neurons}

To determine whether LSd/MS vGAT neurons are functionally connected to LH vGAT neurons in the $\mathrm{LH}$, we transduced LSd/MS vGAT neurons with ChR2-eYFP and LH vGAT neurons with control mCherry, respectively, in the same vGAT-Cre transgenic mice and performed ChR2-assisted circuit mapping in acute brain slices containing LH (Fig. $5 \mathrm{~K}$ ). Experiments were performed in the presence of the sodium channel blocker tetrodotoxin (TTX; $1 \mu \mathrm{M}$ ) and the potassium channel blocker 4-amynopyridine (4-AP; $100 \mu \mathrm{M})$ to detect direct monosynaptic input from septum to $\mathrm{LH}$, as described in our previous study (Sweeney and Yang, 2015). Interestingly, we detected functional GABAergic synaptic currents in $\sim 20 \%$ of recorded LH vGAT neurons. The synaptic currents were eliminated with application of GABAergic receptor blocker picrotoxin, confirming their inhibitory nature (Fig. $5 K$ ). These results suggest that a specific subpopulation of LH vGAT neurons mediates the septum's anorexigenic effect on food intake, although we cannot exclude the potential contribution of other non-vGAT-expressing cell types within LH.

\section{Activation of LH vGAT neurons blocks septal suppression of feeding}

Because inhibitory septal inputs to LH reduce feeding (Fig. 5 F, I) and septal vGAT neurons provide functional inhibitory connec- 
A

B

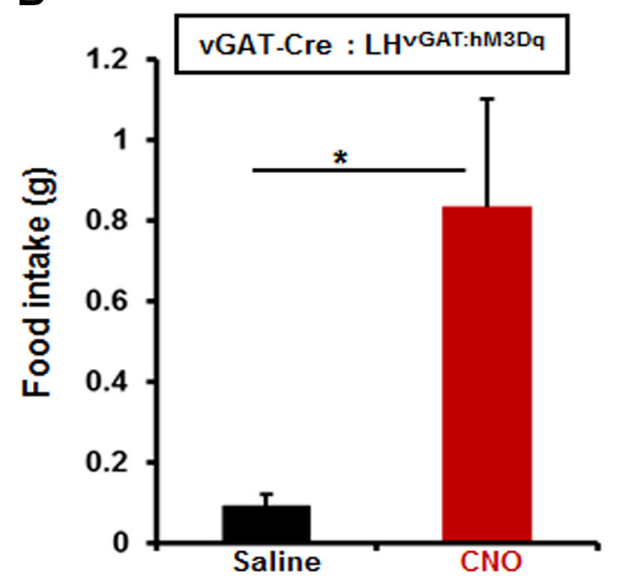

C

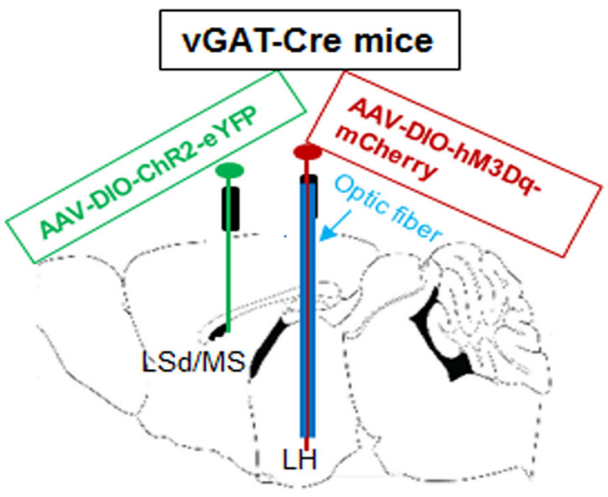

D

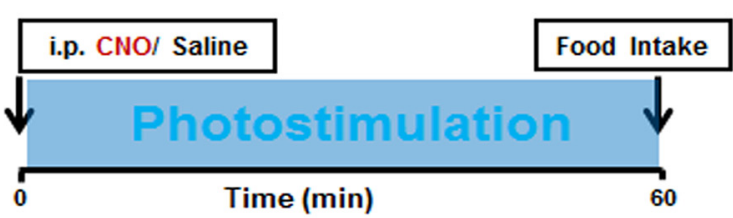

E

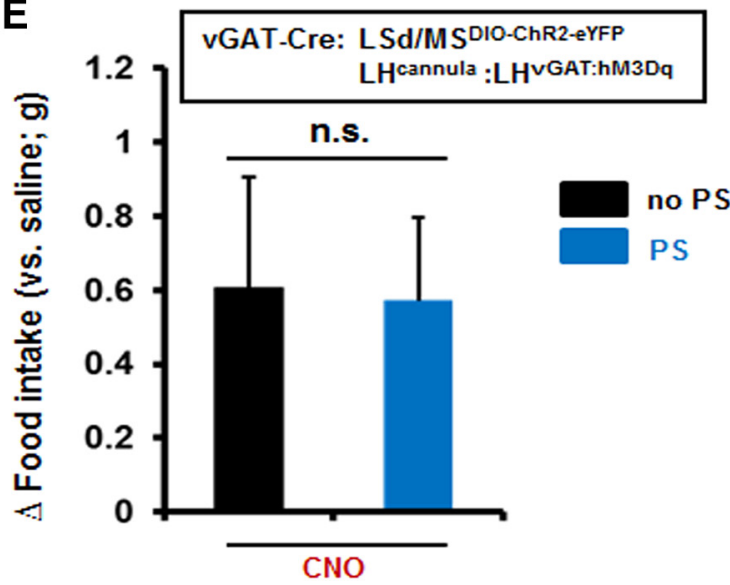

Figure 6. Chemogenetic activation of LH vGAT neurons evokes feeding and blocks septal vGAT suppression of food intake. $\boldsymbol{A}$, Experimental timeline for chemogenetic experiments. Mice were injected with saline or CNO and food intake was measured $60 \mathrm{~min}$ after intraperitoneal injections. $\boldsymbol{B}$, Feeding behavioral assays showing that food intake is increased after CNO injections in mice transduced with the DREADD-hM3Dq in LH vGAT neurons ( $n=6$ mice). C, Schematic showing experimental design to coactivate septal vGAT inputs to LH and LH vGAT neurons. ChR2 and hM3Dq were expressed, respectively, in septal and LH vGAT neurons in vGAT-cre mice and a fiber-optic cannula was inserted above the LH to photostimulate septal vGAT inputs to LH. $\boldsymbol{D}$, Experimental timeline for occlusion experiments. Intraperitoneal injections of CNO were immediately followed by 60 min of PS or no PS, as shown. $\boldsymbol{E}$, Change in food intake after intraperitoneal CNO injections. For each mouse tested, the change in food intake was calculated by subtracting the amount of food consumed after saline injections from the amount of food consumed after CNO injections. No difference was detected between mice treated with CNO + PS and mice treated with CNO + no PS ( $n=5$ mice). Data represent mean \pm SEM. ${ }^{*} p<0.05$, n.s. (not significant).

tions to LH vGAT neurons (Fig. $5 K$ ), we next investigated whether chemogenetic activation of LH vGAT neurons would facilitate feeding. In support of the hypothesis that septal neurons reduce feeding by inhibiting the activity of LH vGAT neurons, chemogenetic activation of LH vGAT neurons robustly increased food intake (Fig. $6 B ; t_{(5)}=2.76, p=0.04$; Student's paired $t$ test; $n=6$ mice). We next tested whether activation of LH vGAT neurons could occlude the reduction in feeding observed after PS of septal vGAT inputs to the LH. To test this prediction, we expressed the protein of ChR2 in septal vGAT neurons and inserted an optic cannula into LH (Fig. 6C). In the same mice, to activate LH vGAT neurons selectively, we expressed hM3Dq in LH vGAT neurons (Fig. 6C). PS of septal vGAT inputs in LH did not significantly affect feeding during chemogenetic activation of LH vGAT neurons (Fig. $6 E ; t_{(4)}=0.20, p=0.85$; Student's paired $t$ test; $n=5$ mice). These findings suggest that activation of $\mathrm{LH}$ vGAT neurons is sufficient to block the anorexic effects of septal vGAT inputs to LH.

\section{Discussion}

Feeding behavior is an essential process that is maintained by multifaceted neural circuits primarily residing in the hypothalamus and hindbrain (Williams and Elmquist, 2012; Schwartz and Zeltser, 2013; Sternson et al., 2013; Sternson and Atasoy, 2014). However, the relative influence of higher-level cognitive and emotional brain circuits to hypothalamic control of feeding remains underexplored. Here, we characterized the role of the septum, a brain region understudied in metabolic control but heavily implicated in stress, anxiety, and aggression (Spiegel et al., 1940; Albert et al., 1976; Sparks and LeDoux, 2000; Sheehan et al., 2004; Singewald et al., 2011), in the control of food intake. Although previous studies have described a role for the septum in feeding behavior (Scopinho et al., 2008; Mitra et al., 2014; Mitra et al., 2015; Terrill et al., 2016), the cell types and neural circuits responsible for septal control of feeding have remained elusive. In the present study, we found that activation of 
vGAT-expressing neurons in the septum decreases feeding by projecting to the $\mathrm{LH}$ and inhibition of these neurons increases food intake (Figs. 1; 4, 5, 6).

\section{Septal vGAT neurons suppress food intake}

Our results demonstrate that septal vGAT neurons reduce food intake without apparent changes in anxiety and locomotion. Previous studies have investigated the role of septal inputs to hypothalamic nuclei in stress and anxiety behavior (Bakshi et al., 2007; Singewald et al., 2011; Anthony et al., 2014; Mitra et al., 2015). Based in large part on these and other studies, it was believed that lateral septum reduces anxiety via projections to the hypothalamus. A recent report, however, demonstrated that a subset of CRF-2 (corticotrophin-releasing factor 2)-expressing neurons in the lateral septum increase stress-induced anxiety by projecting to the anterior hypothalamus (Anthony et al., 2014). In the present study, we find that septal inputs to LH reduce feeding (Figs. 4, 5). Given the shared function of septal-hypothalamic circuits in stress and feeding (Bakshi et al., 2007; Singewald et al., 2011; Anthony et al., 2014; Mitra et al., 2015), these neural circuits may represent promising targets for circuit specific mechanisms governing the complex interactions among feeding, stress, and emotion. Future studies are needed to investigate the individual circuits from septum to hypothalamus for feeding and anxiety and to determine whether these circuits are distinct or overlapping.

\section{LH mediates septal vGAT neural suppression of food intake}

Our feeding assays and neural circuit analysis demonstrate that septal vGAT neural projections to the LH reduce food intake and that these septal neurons provide functional inhibitory connections to a subpopulation of vGAT neurons localized in the LH. Consistently, LH vGAT-expressing neurons have been shown to be critical for driving consummatory behaviors (Jennings et al., 2015; Navarro et al., 2015; Nieh et al., 2015; Wu et al., 2015). Consistent with these past findings, our chemogenetic experiments indicate that activation of LH vGAT neurons profoundly enhances food intake (Fig. 6B). It appears that LH vGAT neurons may have a specialized role in driving nonhomeostatic or compulsive drive to consume food because a recent study showed that LH vGAT neurons drive consummatory behaviors regardless of caloric content or even biological relevance (Navarro et al., 2015). These findings are consistent with classical theories linking LH function and feeding to mesolimbic dopamine circuitry (Wise et al., 1978; Wise et al., 1981; Yeomans, 1982; Nieh et al., 2015; Barbano et al., 2016; Nieh et al., 2016). Furthermore, recent findings demonstrate that LH vGAT neurons are capable of increasing dopamine levels in nucleus accumbens by inhibiting local inhibitory neurons in ventral tegmental area (Nieh et al., 2016). Our results indicate that septal vGAT neurons provide upstream inhibitory inputs to LH vGAT neurons (Fig. 5K). However, it remains unclear whether inhibitory septal inputs to LH vGAT neurons are capable of suppressing the output of LH vGAT neurons to the mesolimbic dopamine circuitry. Nonetheless, our results support a model in which septal vGAT neurons reduce feeding, at least in part by suppressing the activity of the mesolimbic dopamine circuitry through LH vGAT neurons. Future studies are needed, however, to more fully test the potential interactions among septal vGAT neurons, the mesolimbic dopamine circuitry, and motivated behavior.

\section{Conclusions}

It appears that LH vGAT neurons are poised to integrate multiple inputs originating from distinct brain regions to adaptively mod- ulate motivational behaviors, including feeding. Interestingly, the inhibitory GABAergic inputs projecting to LH target opposing LH cell populations to differentially affect feeding behavior. For instance, the GABAergic neurons localized in the bed nucleus of the stria terminalis project to glutamatergic neurons localized in the LH to increase food intake (Jennings et al., 2013). In contrast, the GABAergic neurons in nucleus accumbens project to LH GABAergic neurons to decrease feeding (O'Connor et al., 2015), similar to the septum, as demonstrated in the present study. Together, these findings highlight the importance and necessity of cell-type- and projection-specific targeting approaches to assigning neural circuit functions to behavior because seemingly identical presynaptic inputs can have opposing behavioral effects depending on the origin of the input and the postsynaptic cell type. Further work is needed to determine why seemingly identical presynaptic inputs interact preferentially with opposing postsynaptic targets in LH (Jennings et al., 2013; O'Connor et al., 2015). Nevertheless, we propose that neural circuits providing upstream inhibitory input to LH vGAT neurons represent promising therapeutic targets for future circuit-specific approaches to pathological conditions related to reward and motivation.

\section{References}

Albert DJ, Richmond SE (1976) Hyperactivity and aggressiveness following infusions of local anesthtic into the lateral septum or surrounding stuructures. Behav Biol 18:211-226. CrossRef Medline

Alexander GM, Rogan SC, Abbas AI, Armbruster BN, Pei Y, Allen JA, Nonneman RJ, Hartmann J, Moy SS, Nicolelis MA, McNamara JO, Roth BL (2009) Remote control of neuronal activity in transgenic mice expressing evolved G protein-coupled receptors. Neuron 63:27-39. CrossRef Medline

Anand BK, Brobeck JR (1951) Localization of a "feeding center" in the hypothalamus of the rat. Proc Soc Exp Biol Med 77:323-324. CrossRef Medline

Anthony TE, Dee N, Bernard A, Lerchner W, Heintz N, Anderson DJ (2014) Control of stress-induced persistent anxiety by an extra-amydala septohypothalamic circuit. Cell 156:522-536. CrossRef Medline

Aponte Y, Atasoy D, Sternson SM (2011) AGRP neurons are sufficient to orchestrating feeding behavior rapidly and without training. Nat Neurosci 14:351-355. CrossRef Medline

Armbruster BN, Li X, Pausch MH, Herlitze S, Roth BL (2007) Evolving the lock to fit the key to create a family of $\mathrm{G}$ protein-coupled receptors potently activated by an inert ligand. Proc Natl Acad Sci U S A 104: 5163-5168. CrossRef Medline

Bakshi VP, Newman SM, Smith-Roe S, Jochman KA, Kalin NH (2007) Stimulation of lateral septum CRF2 receptors promotes anorexia and stress-like behaviors: functional homology to CRF1 receptors in basolateral amygdala. J Neurosci 27:10568-10577. CrossRef Medline

Barbano MF, Wang HL, Morales M, Wise RA (2016) Feeding and reward are differentially induced by activating GABAergic lateral hypothalmic projections to VTA. J Neurosci 36:2975-2985. CrossRef Medline

Berthoud HR, Münzberg H (2011) The lateral hypothalamus as integrator of metabolic and environmental needs: from electrical self-stimulation to opto-genetics. Physiol Behav 104:29-39. CrossRef Medline

Betley JN, Cao ZF, Ritola KD, Sternson SM (2013) Parallel, redundant circuit organization for homeostatic control of feeding behavior. Cell 155: 1337-1350. CrossRef Medline

Brown JA, Woodworth HL, Leinninger GM (2015) To ingest or rest? Specialized roles of lateral hypothalamic area neurons in coordinating energy balance. Front Syst Neurosci 9:9. CrossRef Medline

Davidson TL, Chan K, Jarrard LE, Kanoski SE, Clegg DJ, Benoit SC (2009) Contributions of the hippocampus and medial prefrontal cortex to energy and body weight regulation. Hippocampus 19:235-252. CrossRef Medline

Delgado JM, Anand BK (1953) Increase of food intake induced by electrical stimulation of the lateral hypothalamus. Am J Physiol 172: 162-168. Medline

Gong Y, Xu L, Wang H, Guo F, Sun X, Gao S (2013) Involvements of the lateral hypothalamic area in gastric motility and its regulation by the lateral septum. Gen Comp Endocrinol 194, 275-285. CrossRef Medline

Gradinaru V, Zhang F, Ramakrishnan C, Mattis J, Prakash R, Diester I, Gos- 
hen I, Thompson KR, Deisseroth K (2010) Molecular and cellular approaches for diversifying and extending optogenetics. Cell 141:154-165. CrossRef Medline

Grossman SP, Grossman L (1982) Iontophoretic injections of kainic acid into the rat lateral hypothalamus: effects on ingestive behavior. Physiol Behav 29:553-559. CrossRef Medline

Grossman SP, Dacey D, Halaris AE, Collier T, Routtenberg A (1978) Aphagia and adipsia after preferential destruction of nerve cell bodies in hypothalamus. Science 202:537-539. CrossRef Medline

Hsu TM, et al., (2015) Hippocampal ghrelin signaling mediates appetite through lateral hypothalmic orexin pathways. eLife 4: pii: e11190. CrossRef Medline

Jennings JH, Rizzi G, Stamatakis AM, Ung RL, Stuber GD (2013) The inhibitory circuit architecture of the lateral hypothalamus orchestrates feeding. Science 341:1517-1521. CrossRef Medline

Jennings JH, Ung RL, Resendez SL, Stamatakis AM, Taylor JG, Huang J, Veleta K, Kantak PA, Aita M, Shilling-Scrivo K, Ramakrishnan C, Deisseroth K, Otte S, Stuber GD (2015) Visualizing hypothalamic network dynamics for appetitive and consummatory behaviors. Cell. 160, 516527. CrossRef Medline

Kanoski SE, Fortin SM, Ricks KM, Grill HJ (2013) Ghrelin signaling in the ventral hippocampus stimulates learned and motivational aspects of feeding via PI3K-Akt signaling. Biol Psychiatry 73:915-923. CrossRef Medline

Kelly J, Rothstein J, Grossman SP (1979) GABA and hypothalamic feeding Systems I. Topographic analysis of the effects of microinjections of muscimol. Physiol Behav 23:1123-1134. CrossRef Medline

Mitra A, Lenglos C, Timofeeva E (2014) Activation of GABAA and GABAB receptors in the lateral septum increases sucrose intake by differential stimulation of sucrose licking activity. Behav Brain Res 273:82-88. CrossRef Medline

Mitra A, Lenglos C, Timofeeva E (2015) Inhibition in the lateral septum increases sucrose intake and decreases anorectic effects of stress. Eur J Neurosci 41:420-433. CrossRef Medline

Navarro M, Olney JJ, Burnham NW, Mazzone CM, Lowery-Gionta EG, Pleil KE, Kash TL, Thiele TE (2015) Lateral hypothalamus GABAergic neurons modulate consummatory behaviors regardless of the caloric content or biological relevance of the consumed stimuli. Neuropsychopharmacology 41:1501-1512. CrossRef Medline

Nieh EH, Vander Weele CM, Matthews GA, Presbrey KN, Wichmann R, Leppla CA, Izadmehr EM, Tye KM (2016) Inhibitory input from the lateral hypothalamus to the ventral tegmental area disinhibits dopamine neurons and promotes behavioral activation. Neuron 90:1286-1298. CrossRef Medline

Nieh EH, Matthews GA, Allsop SA, Presbrey KN, Leppla CA, Wichmann R, Neve R, Wildes CP, Tye KM (2015) Decoding neural circuits that control compulsive sucrose seeking. Cell 160:528-541. CrossRef Medline

O'Connor EC, Kremer Y, Lefort S, Harada M, Pascoli V, Rohner C, Lüscher C (2015) Accumbal D1R neurons projecting to lateral hypothalamus authorize feeding. Neuron 88:553-564. CrossRef Medline

Parent MB, Darling JN, Henderson YO (2014) Remembering to eat: hippocampal regulation of meal onset. Am J Physiol Regul Integr Comp Physiol 306:R701-R713. CrossRef Medline

Petreanu L, Huber D, Sobczyk A, Svoboda K (2007) Channelrhodopsin-2assisted circuit mapping of long-range callosal projections. Nat Neurosci 10:663-668. CrossRef Medline

Qi Y, Yang Y (2015) Hunger states control the directions of synaptic plasticity via switching cell type-specific subunits of NMDA receptors. J Neurosci 35:13171-13182. CrossRef Medline

Risold PY, Swanson LW (1997) Chemoarchitecture of the rat lateral septal nucleus. Brain Res Rev 24:115-195. CrossRef Medline

Sartor GC, Aston-Jones GS (2012) A septal-hypothalamic pathway drives orexin neurons, which is necessary for conditioned cocaine preference. J Neurosci 32:4623-4631. CrossRef Medline

Schwartz GJ, Zeltser LM (2013) Functional organization of neuronal and humoral signals regulating feeding behavior. Annu Rev Nutr 33:1-21. CrossRef Medline
Scopinho AA, Resstel LB, Corrêa FM (2008) Alpha(1)-adrenoceptors in the lateral septal area modulate food intake behavior in rats. Br J Pharmacol 155:752-756. CrossRef Medline

Sheehan TP, Chambers RA, Russell DS (2004) Regulation of affect by the lateral septum: implications for neuropsychiatry. Brain Res Rev 46: 71-117. CrossRef Medline

Singewald GM, Rjabokon A, Singewald N, Ebner K (2011) The modulatory role of the lateral septum on neuroendrocrine and behavioral stress responses. Neuropsychopharmacology 36:793-804. CrossRef Medline

Sparks, P.D., LeDoux, J.E (2000) The septal complex as seen through the context of fear. In: The behavioral neuroscience of the septal region (Numan R, ed), pp 234-269. New York: Springer.

Spiegel EA, Miller HR, Oppenheimer MJ (1940) Forebrain and rage reactions. J Neurophysiol 3:538-548.

Stachniak TJ, Ghosh A, Sternson SM (2014) Chemogenetic synaptic silencing of neural circuits localizes a hypothalamus midbrain pathway for feeding behavior. Neuron 82:797-808. CrossRef Medline

Stamatakis AM, Van Swieten M, Basiri ML, Blair GA, Kantak P, Stuber GD (2016) Lateral hypothalmic area glutamatergic neurons and their projections to the lateral habenula regulate feeding and reward. J Neurosci 36 : 302-311. CrossRef Medline

Sternson SM, Atasoy D (2014) Agouti-related protein neuron circuits that regulate appetite. Neuroendocrinology 100:95-102. CrossRef Medline

Sternson SM, Nicholas Betley J, Cao ZF (2013) Neural circuits and motivational processes for hunger. Curr Opin Neurobiol 23:353-360. CrossRef Medline

Stricker EM, Swerdloff AF, Zigmond MJ (1978) Intrahypothalamic injections of kainic acid produce feeding and drinking deficits in rats. Brain Res 158:470-473. CrossRef Medline

Stuber GD, Wise RA (2016) Lateral hypothalmic circuits for feeding and reward. Nat Neurosci 19:198-205. CrossRef Medline

Sweeney P, Yang Y (2015) An excitatory ventral hippocampus to lateral septum circuit that suppresses feeding. Nat Commun 6:10188. CrossRef Medline

Sweeney P, Levack R, Watters J, Xu Z, Yang Y (2016) Caffeine increases food intake while reducing anxiety-related behaviors. Appetite 101:171-177. CrossRef Medline

Terrill SJ, Jackson CM, Greene HE, Lilly N, Maske CB, Vallejo S, Williams DL (2016) Role of lateral septum glucagon-like peptide 1 receptors in food intake. Am J Physiol Regul Integr Comp Physiol 311:R124-R132. CrossRef Medline

Urstadt KR, Stanley BG (2015) Direct hypothalamic and indirect transpallidal, trans-thalamic, or trans-septal control of accumbens signaling and their roles in food intake. Front Syst Neurosci 9:8. CrossRef Medline

Williams KW, Elmquist JK (2012) From neuroanatomy to behavior: central integration of peripheral signals regulating feeding behavior. Nat Neurosci 15:1350-1355. CrossRef Medline

Wise RA, Bozarth MA (1981) Brain substrates for reinforcement and drug self-administration. Prog Neuropsychopharmacol 5:467-474. CrossRef Medline

Wise RA, Spindler J, deWit H, Gerberg GJ (1978) Neuroleptic-induced "anhedonia" in rats: pimozide blocks reward quality of food. Science 201: 262-264. CrossRef Medline

Wu Z, Kim ER, Sun H, Xu Y, Mangieri LR, Li DP, Pan HL, Xu Y, Arenkiel BR, Tong Q (2015) GABAergic projections from lateral hypothalamus to paraventricular hypothalamic nucleus promote feeding. J Neurosci 35: 3312-3318. CrossRef Medline

Xu W, Südhof TC (2013) A neural circuit for memory specificity and generalization. Science 339:1290-1295. CrossRef Medline

Yang L, Qi Y, Yang Y (2015) Astrocytes control food intake by inhibiting AGRP neuron activitiy via adenosine A1 receptors. Cell Rep 11:798-807. CrossRef Medline

Yeomans JS (1982) The cells and axons mediating medial forebrain bundle reward. In: The neural basis of feeding and reward (Hoebel BG, Novin D, eds), pp 405-417. Location: Haernstitute. 